\title{
Physician perspectives on the burden and management of asthma in six countries: The Global Asthma Physician Survey (GAPS)
}

Kenneth R. Chapman ${ }^{1}$, David Hinds ${ }^{2 *}$, Peter Piazza ${ }^{3}$, Chantal Raherison $^{4}$, Michael Gibbs ${ }^{5}$, Timm Greulich ${ }^{6}$, Kenneth Gaalswyk ${ }^{7}$, Jiangtao Lin $^{8}$, Mitsuru Adachi ${ }^{9}$ and Kourtney J. Davis ${ }^{2}$

\begin{abstract}
Background: Despite recognition of asthma as a growing global issue and development of global guidelines, asthma treatment practices vary between countries. Several studies have reported patients' perspectives on asthma control. This study presents physicians' perspectives and strategies for asthma management.
\end{abstract}

Methods: Physicians seeing $\geq 4$ adult patients with asthma per month in Australia, Canada, China, France, Germany, and Japan were surveyed ( $N=1809 ; \approx 300$ per country). A standardised questionnaire was developed for this study and administered by telephone, online or face-to-face. Statistics were weighted to account for the sampling scheme.

Results: Physicians estimated that $71 \%$ of their adult patients received maintenance medication, with adherence monitored by $76-97 \%$ of physicians. Perceived major barriers to patient adherence included: patients taking treatment as needed; acceptance of symptoms; and patients not perceiving treatment benefits. Written action plans (37\%) and technology (15\%) were seldom employed by physicians to aid patients' asthma management. Physicians rarely (10\%) used validated patient-reported questionnaires to monitor asthma control, instead monitoring selected symptoms, exacerbations, and/or lung function measurements. Awareness of single maintenance and reliever therapy (SMART/MART) varied among countries (56-100\%); although most physicians (72\%) had prescribed SMART/ MART, the majority (91\%) co-prescribed a short-acting bronchodilator at least some of the time.

Conclusions: These results show that physicians generally do not employ standardised tools to monitor asthma control or to manage its treatment and that despite high awareness of SMART/MART, the strategy appears to be commonly misapplied. Better education for patients and physicians is required to improve asthma management and resulting patient outcomes.

Keywords: Asthma, surveys and questionnaires, guideline adherence, patient compliance, physicians' practice patterns, disease management

\section{Background}

Asthma is a global health problem that imposes a substantial burden on healthcare systems and on society through impaired quality of life and loss of productivity in the workplace $[1,2]$. Despite significant research effort into the development of effective therapies and evidence-based treatment guidelines [3-5], individuals

\footnotetext{
* Correspondence: david.r.hinds@gsk.com

${ }^{2}$ Real World Evidence \& Epidemiology, GlaxoSmithKline, 1250 South

Collegeville Road, Collegeville, PA 19426, USA

Full list of author information is available at the end of the article
}

with asthma throughout the world do not achieve asthma control [6-10].

Both global and national guidelines have been developed to standardise and improve asthma management, thereby aiming to help patients optimise asthma control. After a collaboration between the American National Heart, Lung and Blood Institute and the World Health Organization in 1993, the Global Initiative for Asthma (GINA) was established and its 'Global Strategy for Asthma Management and Prevention' reports have been updated annually since 2002 [11]. Medical associations 
in many countries have also produced national guidelines for the management of asthma [12-14]. These guidelines provide both therapeutic and non-pharmacological recommendations for optimal management of asthma, as well as defining levels of asthma control.

Guidelines have evolved with changing treatment patterns in asthma, including the establishment of inhaled corticosteroids (ICS) as the cornerstone of treatment for patients with persistent asthma, and the incorporation of ICS combined with long-acting $\beta_{2}$-agonists (LABAs) [11]. Guidelines have also evolved with changing dosing strategies such as the option of prescribing an ICS/formoterol combination in a single inhaler as both maintenance and reliever therapy, rather than using separate formoterol or another short-acting $\beta_{2}$-agonist (SABA) for rapid symptom relief (rescue use) [11]. Use of single maintenance and reliever therapy (known as SMART or MART - for simplicity MART will be used hereafter) has been reported to show similar efficacy in clinical trial settings compared with alternative ICS/LABA combinations with additional SABA use, especially in patients with a history of exacerbations $[3,15]$.

Multiple studies of patients with asthma have revealed the variable levels of asthma control achieved worldwide. The Asthma Insights and Reality (AIR) studies of patients from regions including North America [16], Europe [6], and the Asia-Pacific region [7] in the late 1990s and early 2000s demonstrated that levels of asthma control were substantially below the goals set out in the GINA guidelines [11] and that patients tended to underestimate the severity of their asthma symptoms [6, 7]. More recently, the Asthma Insight and Management (AIM) surveys of patients in the USA [17], Latin America [8], Canada, and Europe [18], and the REcognise Asthma and LInk to Symptoms and Experience (REALISE) surveys of European [9] and Asian [10] patients found that the issues identified in the AIR studies are still present.

Several single-country studies have also highlighted the variability of asthma control: one survey of patients in China reported that only $28.7 \%$ achieved total control as defined in the GINA guidelines [19], while a second survey reported this figure to be $40.5 \%$ [20]. A Canadian study of both patients and primary care physicians designed to eliminate any potential bias associated with telephone-based surveys of asthma control also reported low levels of total asthma control (23\%), and found that physicians overestimated patients' levels of control [21].

While most surveys to date have examined the perspectives of patients, it is also important to understand the perspectives of physicians treating these patients. The 2005 Global Asthma Physician and Patient (GAPP) study in 16 countries reported differences between 'real-world' treatment practices and those recommended in the GINA guidelines [22]; these have been similarly observed in several other country-specific surveys [23-25]. The GAPP survey also revealed considerable differences between patients' and physicians' perspectives on asthma education, treatment adherence and potential side effects of medication [22]. The second phase of the REALISE Asia study surveyed 375 physicians across Asia and reported differences between physicians' and patients' definitions of asthma control, with both groups overestimating patients' levels of control [26]. These studies demonstrate the importance of surveying physicians as well as patients to gain a full understanding of perspectives and management practices.

The present study, the Global Asthma Physician Survey (GAPS), aimed to provide a current picture of asthma management practices in different countries by assessing physicians' perspectives regarding the burden, management, and treatment of asthma, including management with and 'real-world' implementation of MART dosing.

\section{Methods}

\section{Study Design and Participants}

GAPS (GSK study number PRJ2509) was a cross-sectional survey of general practice or internal medicine physicians in Australia, Canada, China, France, Germany, and Japan who routinely treated adult patients with asthma ( $\geq 4 \mathrm{pa}-$ tients per month) conducted between May and September 2015. In France and Germany, participants were drawn from a probability-based national sample frame proportional to the distribution of physicians by geographic strata. In Australia and Japan, participants were sampled from a nationally representative online opt-in panel. In Canada, participants were drawn from both a national sample frame and a nationally representative opt-in panel, while in China, the sampling plan was consistent with the tiered system of hospitals that deliver primary care: internal medicine physicians were recruited from hospitals in five major cities (Beijing, Shanghai, Guangzhou, Chengdu and Wuhan; approximately 60 physicians per city), with the proportion of physicians from each hospital within a city adjusted according to the size (tier) of the hospital.

\section{Survey Administration}

All surveys were conducted in the local language(s). In France and Germany, surveys were administered by telephone. In Australia and Japan, surveys were administered online. In Canada, surveys were administered both by telephone (103 physicians, national sample frame) and online (204 physicians, opt-in panel). In China, participants were interviewed by professional interviewers and offered either a face-to-face interview with paper questionnaires or a telephone interview. 


\section{Questionnaire}

The questionnaire was developed in conjunction with key external experts (the authors) in the relevant countries with knowledge of local asthma treatment and management practices. It was designed to assess: physicians' beliefs about asthma; knowledge of and adherence to asthma guidelines; perceived barriers to patients' adherence; and asthma management and treatment practices, including management with MART. The full questionnaire (in English; translations were employed as necessary and reviewed by national experts) is provided in the Additional file 1, along with the relevant national guidelines relating to MART in each of the six countries studied (Additional file 2: Table S2).

\section{Data Analysis}

Physicians' responses to survey questions were tabulated and described. Overall statistics were weighted by the number of physicians in each country to adjust for variations in country size. Country-specific data were weighted by known demographic parameters of that country from the sampling frame and available government statistics using the software SAS version 9.3 (Cary, NC, USA).

\section{Results}

Overall 1809 physicians from Australia, Canada, China, France, Germany, and Japan completed the survey, with approximately 300 physicians from each country (Table 1). Physician age, gender and practice type varied considerably between countries. Physicians in France, Germany, and Japan tended to be older, while physicians in France and Japan were less likely to have ever participated in continuing medical education on asthma.

Response rates ranged from $12 \%$ in Canada to $54 \%$ in China, and the average survey time was 21 minutes. Physicians' estimates of the proportions of their adult patients treated with maintenance asthma medication were relatively consistent ( $71 \%$ overall), ranging from 63\% (France) to $77 \%$ (Germany and Japan).

\section{General Perspectives on Asthma}

Overall, $83 \%$ of physicians (range: 69\% in France to $88 \%$ in Australia and Germany) surveyed believed that the longterm health outlook for patients with asthma has improved compared with 10 years ago. The primary reason for this in all countries, given by $90 \%$ of these physicians, was the increased options for and/or improvement in asthma medications and devices. There was considerable variation between countries in other reasons given for the

Table 1 Demographics of physician survey respondents

\begin{tabular}{|c|c|c|c|c|c|c|c|}
\hline & $\begin{array}{l}\text { Total } \\
N=1809\end{array}$ & $\begin{array}{l}\text { Canada } \\
N=307\end{array}$ & $\begin{array}{l}\text { France } \\
N=301\end{array}$ & $\begin{array}{l}\text { Germany } \\
N=300\end{array}$ & $\begin{array}{l}\text { Australia } \\
N=300\end{array}$ & $\begin{array}{l}\text { China } \\
N=300\end{array}$ & $\begin{array}{l}\text { Japan } \\
N=301\end{array}$ \\
\hline \multicolumn{8}{|l|}{ Age (years) } \\
\hline$<35$ & 7 & 13 & 10 & 1 & 9 & 12 & - \\
\hline $35-44$ & 25 & 25 & 16 & 15 & 23 & 46 & 13 \\
\hline $45-54$ & 30 & 27 & 25 & 30 & 31 & 35 & 29 \\
\hline $55-64$ & 28 & 23 & 40 & 39 & 25 & 8 & 41 \\
\hline$>65$ & 9 & 12 & 9 & 16 & 13 & - & 16 \\
\hline \multicolumn{8}{|l|}{ Gender } \\
\hline Male & 61 & 56 & 63 & 59 & 59 & 40 & 86 \\
\hline \multicolumn{8}{|l|}{ Type of practice } \\
\hline Single specialty or solo GP & 32 & 56 & 62 & 85 & 12 & - & 23 \\
\hline Multi-speciality or group GP & 36 & 21 & 36 & 14 & 88 & 5 & 72 \\
\hline Hospital or hospital clinic & 31 & 15 & 1 & - & - & 95 & 5 \\
\hline Continuing medical education on Asthma (ever) & 79 & 94 & 69 & 98 & 92 & 92 & 54 \\
\hline Mean number of patients with asthma seen per month (n) & 40 & 56 & 15 & 31 & 68 & 37 & 51 \\
\hline \multicolumn{8}{|l|}{ Ages of patients seen ${ }^{a}$} \\
\hline Paediatric & 13 & 21 & 24 & 5 & 33 & 2 & 11 \\
\hline Adolescent & 12 & 17 & 19 & 9 & 21 & 6 & 11 \\
\hline Adult & 78 & 63 & 57 & 86 & 46 & 94 & 80 \\
\hline Mean percentage of adult patients on maintenance medication & 71 & 73 & 63 & 77 & 66 & 68 & 77 \\
\hline
\end{tabular}

Values are \% except where stated otherwise. '-' represents values of $0 \%$ or $<1 \%$. Percentage values within categories may sum to $<100 \%$ or $>100 \%$ due to

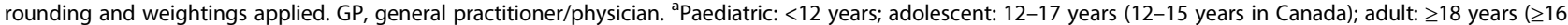
years in Canada) 
perceived improved outlook over the last 10 years (Additional file 2: Table S1): improved understanding by physicians was selected by only $2 \%$ of respondents in Japan, but by $45 \%$ of respondents in China, while improved understanding by patients varied from $<1 \%$ (Australia and Japan) to 38\% (China).

The major barriers to medication adherence were perceived to be: i) patients only taking maintenance treatment as needed; ii) patients adapting to or tolerating ongoing asthma symptoms; and iii) patients not perceiving the benefit of the treatment. Differences in views between countries are presented in Table 2 .

\section{Perspectives on Asthma Management}

Of physicians surveyed, $87 \%$ reported monitoring adherence to maintenance medication (range: $76 \%$ in Canada to $97 \%$ in China), while monitoring reliever medication usage was reported by $89 \%$ of physicians. Most physicians reported monitoring adherence and reliever medication use through patient interactions: asking directly (91\% and 93\% of physicians overall for maintenance and reliever use, respectively) or estimating from patient interviews (80\% and $78 \%$, respectively). Fewer physicians estimated medication use by objective means such as the timing of prescription refill requests $(57 \%$ and $50 \%$ for maintenance and reliever medications, respectively) or checking prescription labels for the date dispensed (38\% and $28 \%$ for maintenance and reliever medications, respectively). Trends were consistent between countries.

Written action plans were infrequently implemented with patients. Physicians estimated that only $37 \%$ of their patients were issued with a written asthma action plan, though this varied by country from 30\% (China) to 50\% (Japan). Technology was generally not used in asthma management: overall only $15 \%$ of physicians reported using any mobile, online or digital tools, ranging from $8 \%$ (Japan) to $25 \%$ (China).
Physician practices for assessing asthma control also varied considerably among countries (Table 3 ); in particular, the data from physicians in China differed noticeably from other countries. Monitoring symptom frequency was the most commonly used method in China, used by $95 \%$ of physicians, but was used by only $8 \%$ of physicians in Japan, where monitoring exacerbations was the most frequent response. In France and Germany, lung function measures (spirometry) were the most frequently used method to assess control. Monitoring use of reliever SABAs for symptom control was the most common method of assessing control in Australia and Canada. Use of validated patient-reported questionnaires was low in all countries (used by $10 \%$ of physicians overall).

The majority of physicians surveyed believed that their adult patients received the treatment that the physician considered to be best for them at least most of the time (86\% overall, ranging from $76 \%$ in Japan to $97 \%$ in Germany). The most commonly selected reason (given by $59 \%$ of physicians overall) why patients do not receive the treatment that physicians believed to be the best for them was that patients failed to understand the importance of using the medication. The next most commonly given reason (37\% overall) was 'patient factors' such as compliance, lifestyle/habits and poor follow-up; this reason was rated very differently between countries, given by $84 \%$ of physicians in Australia and $63 \%$ in Canada, but only $2 \%$ in China.

\section{Perspectives on MART}

The majority of physicians surveyed $(n=1479,83 \%)$ reported being aware of MART; of these physicians, the majority ( $\mathrm{n}=1286,86 \%)$ had prescribed MART. Awareness and use of this strategy varied considerably by country (Fig. 1). Subsequent questions regarding MART administration were asked only of physicians who answered affirmatively that they had ever prescribed MART.

Table 2 Percentage of physicians reporting each barrier to patient adherence as a major problem

\begin{tabular}{|c|c|c|c|c|c|c|c|}
\hline$\%$ of physicians reporting barrier as a major problem & $\begin{array}{l}\text { Total } \\
N=1809\end{array}$ & $\begin{array}{l}\text { Canada } \\
N=307\end{array}$ & $\begin{array}{l}\text { France } \\
N=301\end{array}$ & $\begin{array}{l}\text { Germany } \\
N=300\end{array}$ & $\begin{array}{l}\text { Australia } \\
N=300\end{array}$ & $\begin{array}{l}\text { China } \\
N=300\end{array}$ & $\begin{array}{l}\text { Japan } \\
N=301\end{array}$ \\
\hline Patients only take treatment when needed & 61 & 72 & 66 & 31 & 71 & 57 & 68 \\
\hline Patients believe asthma symptoms are normal & 58 & 41 & 57 & 30 & 42 & 61 & 78 \\
\hline Patients don't perceive the benefit of the treatment & 56 & 40 & 55 & 41 & 43 & 45 & 81 \\
\hline Poor inhaler technique & 53 & 52 & 61 & 43 & 52 & 27 & 81 \\
\hline Low patient education level or poor understanding of disease & 52 & 52 & 60 & 54 & 54 & 31 & 70 \\
\hline Low level of patient engagement in disease & 52 & 41 & 63 & 39 & 47 & 31 & 80 \\
\hline Forgetfulness & 45 & 39 & 54 & 24 & 43 & 20 & 78 \\
\hline Troublesome side effects & 45 & 7 & 18 & 15 & 12 & 63 & 72 \\
\hline Corticosteroids are perceived as harmful & 43 & 30 & 20 & 40 & 31 & 47 & 61 \\
\hline The cost of medications & 37 & 56 & 6 & 16 & 26 & 42 & 55 \\
\hline Inconvenience of dosing schedule & 33 & 19 & 31 & 15 & 22 & 20 & 62 \\
\hline
\end{tabular}


Table 3 Practices for assessing asthma control

\begin{tabular}{|c|c|c|c|c|c|c|c|}
\hline$\%$ of physicians using this method & $\begin{array}{l}\text { Total } \\
N=1809\end{array}$ & $\begin{array}{l}\text { Canada } \\
N=307\end{array}$ & $\begin{array}{l}\text { France } \\
N=301\end{array}$ & $\begin{array}{l}\text { Germany } \\
N=300\end{array}$ & $\begin{array}{l}\text { Australia } \\
N=300\end{array}$ & $\begin{array}{l}\text { China } \\
N=300\end{array}$ & $\begin{array}{l}\text { Japan } \\
N=301\end{array}$ \\
\hline Lung function measurement with spirometry (e.g. $\mathrm{FEV}_{1}$ or peak flow) & 42 & 28 & 46 & 57 & 47 & 54 & 24 \\
\hline Frequency of symptoms & 41 & 15 & 28 & 31 & 12 & 95 & 8 \\
\hline Frequency of exacerbations & 41 & 41 & 31 & 9 & 37 & 59 & 43 \\
\hline Frequency of night-time awakenings & 30 & 31 & 8 & 6 & 33 & 70 & 8 \\
\hline Interference with normal activities (excluding work) & 27 & 21 & 15 & 3 & 16 & 60 & 14 \\
\hline Use of reliever SABAs for symptom control & 23 & 42 & 17 & 5 & 53 & 37 & 5 \\
\hline Interference with work or household work & 20 & 16 & 4 & 2 & 7 & 58 & 1 \\
\hline Validated patient-reported outcomes (ACT, ACQ) & 10 & 5 & 29 & 8 & 2 & 13 & 1 \\
\hline Symptoms (unspecified) & 7 & 17 & 1 & 3 & 32 & 1 & 12 \\
\hline Medication use and frequency & 6 & 15 & 1 & 6 & 15 & - & 10 \\
\hline Patient or family feedback & 6 & 12 & 1 & 12 & 15 & - & 9 \\
\hline Ability to exercise/exertion & 5 & 15 & - & 2 & 19 & - & 8 \\
\hline Induced sputum measurement & 5 & 1 & 1 & - & 2 & 15 & - \\
\hline Other responses combined & 37 & 54 & 33 & 45 & 68 & 2 & 61 \\
\hline
\end{tabular}

Responses to survey question: How do you assess asthma control in your adult asthma patients?

Only answers with a response rate of $\geq 15 \%$ in at least one country have been included. '-' represents values of $0 \%$ or $<1 \%$

ACQ Asthma Control Questionnaire, ACT Asthma Control Test, FEV forced expiratory volume in 1 second, SABA short-acting $\beta_{2}$-agonist

Physicians' sources for information about MART were mainly scientific conferences ( $54 \%$ overall; from $17 \%$ in France to $75 \%$ in China) and pharmaceutical sales representatives (49\% overall; from $40 \%$ in China to $74 \%$ in Australia) rather than from local (31\%) or GINA (30\%) guidelines. Conversely, many physicians in China reported obtaining their information from local $(77 \%)$ or GINA (77\%) guidelines. The proportion of ICS/LABA fixed-dose combination inhalers prescribed as MART was $42 \%$ overall, varying from $33 \%$ (Germany) to $47 \%$ (China).
Physicians' perspectives on MART are summarised in Table 4. The most common reason for prescribing MART overall was the severity of symptoms (cited by $35 \%$ of physicians); however, patient factors (such as age, understanding, and compliance) were the most common reason in Australia, Canada, and Germany. In Japan, both patient factors and the presence or risk of exacerbations were the most common reasons to prescribe MART. The mild nature of symptoms was the most common reason overall (38\% of those reporting situations where MART would not be prescribed) for not prescribing MART.

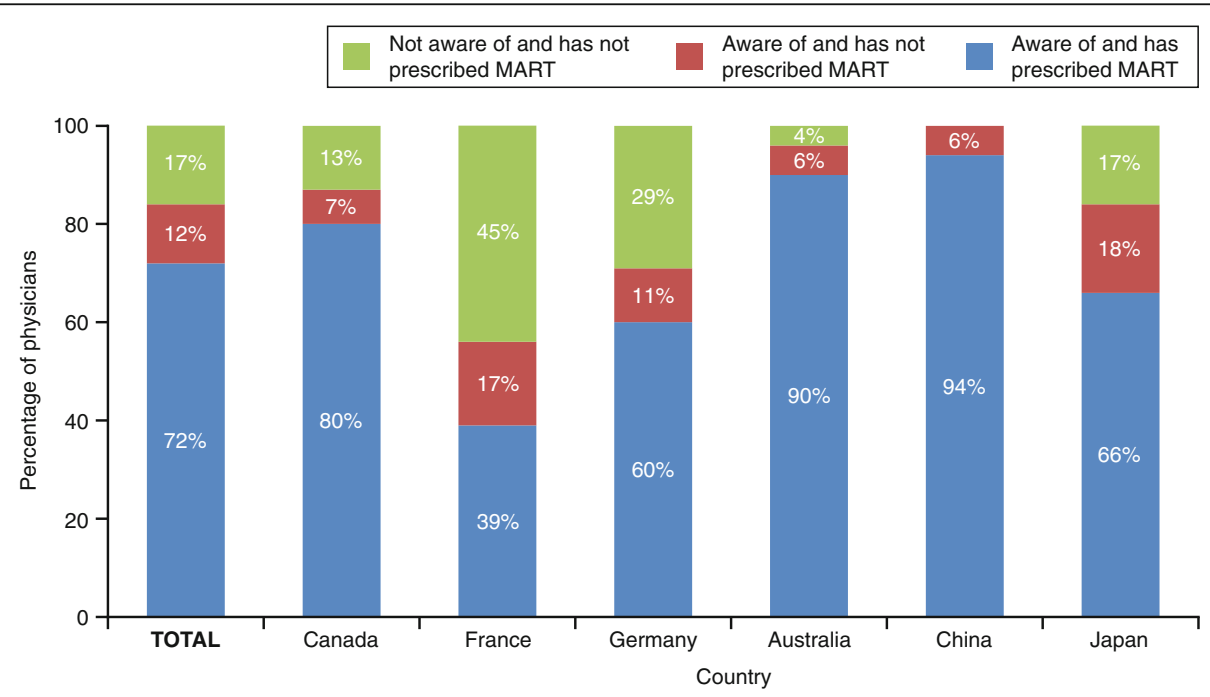

Fig. 1 Awareness and prescribing of MART in different countries. MART, maintenance and reliever therapy. Percentage values within categories may sum to $<100 \%$ or $>100 \%$ due to rounding and weightings applied; calculations were performed using weighted $n$ values 
Table 4 Physicians' perspectives on MART

\begin{tabular}{|c|c|c|c|c|c|c|c|}
\hline$\%$ of physicians giving response & $\begin{array}{l}\text { Total } \\
n=1286\end{array}$ & $\begin{array}{l}\text { Canada } \\
n=248\end{array}$ & $\begin{array}{l}\text { France } \\
n=112\end{array}$ & $\begin{array}{l}\text { Germany } \\
n=180\end{array}$ & $\begin{array}{l}\text { Australia } \\
n=269\end{array}$ & $\begin{array}{l}\text { China } \\
n=281\end{array}$ & $\begin{array}{l}\text { Japan } \\
n=196\end{array}$ \\
\hline \multicolumn{8}{|l|}{ Reasons for prescribing MART } \\
\hline Patients with severe symptoms (daytime/night-time symptoms $\geq 4$ days/week) & 35 & 3 & 15 & 11 & 1 & 79 & 3 \\
\hline Patients with moderate symptoms (daytime/night-time symptoms 2-3 days/week) & 33 & 5 & 16 & 10 & 1 & 72 & 6 \\
\hline Patients with/at risk of exacerbations & 30 & 7 & 12 & 5 & 9 & 51 & 29 \\
\hline Greater convenience for the patient as only one inhaler is required & 22 & 27 & 32 & 15 & 28 & 29 & 6 \\
\hline Patient factors (knowledge/understanding, compliance, age) & 20 & 54 & 5 & 17 & 65 & - & 29 \\
\hline \multicolumn{8}{|l|}{ Reasons for not prescribing MART ${ }^{a}$} \\
\hline Patients with more mild symptoms & 38 & 10 & 8 & 4 & 13 & 64 & 6 \\
\hline Patients with poor adherence & 25 & 13 & 34 & 18 & 18 & 29 & 18 \\
\hline Patients with severe symptoms (daytime/night-time symptoms $\geq 4$ days/week) & 19 & 14 & 14 & 17 & 18 & 25 & 5 \\
\hline Patients with lots of co-morbidities & 14 & 18 & 3 & 16 & 16 & 15 & 10 \\
\hline Patient factors (knowledge/understanding, compliance, age) & 10 & 30 & 14 & 10 & 37 & - & 21 \\
\hline \multicolumn{8}{|l|}{ Prescription of SABA/bronchodilator with MART } \\
\hline Always & 19 & 13 & 27 & 10 & 6 & 33 & 3 \\
\hline Most of the time & 30 & 19 & 29 & 29 & 23 & 42 & 18 \\
\hline Some of the time & 42 & 55 & 37 & 52 & 50 & 23 & 63 \\
\hline Never & 8 & 13 & 7 & 9 & 21 & 1 & 13 \\
\hline \multicolumn{8}{|l|}{ Reasons for prescribing SABAs / bronchodilators with MART ${ }^{\mathrm{b}}$} \\
\hline Patients want an extra reliever to feel safer & 35 & 14 & 28 & 36 & 14 & 59 & 8 \\
\hline Patient familiarity with short-acting-beta medicine & 32 & 19 & 13 & 13 & 18 & 59 & 8 \\
\hline Patient convenience - having an extra reliever on hand & 27 & 4 & 13 & 5 & 3 & 56 & 2 \\
\hline Patients are accustomed to having an extra reliever & 20 & 5 & 19 & 6 & 6 & 35 & 8 \\
\hline \multicolumn{8}{|l|}{ MART dosing instructions provided to pharmacy } \\
\hline Don't write anything different to normal dosing & 32 & 25 & 10 & 29 & 23 & 38 & 37 \\
\hline Write Maintenance Plus Reliever language as a standard choice & 26 & 19 & 27 & 8 & 18 & 41 & 15 \\
\hline Have to create my own text noting maintenance frequency and PRN & 21 & 35 & 54 & 33 & 36 & 1 & 24 \\
\hline Write ICS/LABA as both maintenance and reliever & 15 & 18 & 7 & 13 & 20 & 16 & 17 \\
\hline \multicolumn{8}{|l|}{ MART dosing instructions provided to patients } \\
\hline Verbal instructions to use the ICS/LABA as relief as well as maintenance & 87 & 89 & 91 & 83 & 73 & 93 & 82 \\
\hline Written instructions to use the ICS/LABA as relief as well as maintenance & 59 & 45 & 84 & 81 & 66 & 71 & 24 \\
\hline Verbal instructions to use the ICS/LABA as relief but not maintenance & 14 & 7 & 36 & 20 & 6 & 16 & 6 \\
\hline Written instructions to use the ICS/LABA as relief but not maintenance & 6 & 4 & 30 & 18 & 3 & 1 & 1 \\
\hline \multicolumn{8}{|l|}{ Time/effort required for MART prescribing vs. other maintenance medications ${ }^{c}$} \\
\hline Much more time and effort & 14 & 4 & 1 & 6 & 5 & 24 & 11 \\
\hline Somewhat more time and effort & 40 & 32 & 21 & 38 & 40 & 45 & 42 \\
\hline About the same & 29 & 38 & 68 & 43 & 29 & 19 & 20 \\
\hline Somewhat less time and effort & 13 & 19 & 9 & 9 & 18 & 7 & 21 \\
\hline Much less time and effort & 5 & 7 & 0 & 4 & 7 & 5 & 6 \\
\hline
\end{tabular}

Questions regarding MART administration were asked only of physicians who had prescribed MART. '-' represents values of $0 \%$ or $<1 \%$. For questions with more than five possible responses, the five reasons with the highest overall response rates (with overall response rates of $\geq 10 \%$ ) have been included. Percentage values within categories may sum to $<100 \%$ or $>100 \%$ due to rounding and weightings applied ICS inhaled corticosteroid, LABA long-acting $\beta_{2}$-agonist, MART maintenance and reliever therapy, PRN pro re nata (as needed), SABA short-acting $\beta_{2}$-agonist

${ }^{a}$ Among physicians responding yes to there being situations where MART would not be prescribed: Total ( $\left.n=805\right)$, Canada $(n=151)$, France $(n=70)$, Germany ( $n=93)$, Australia $(n=157)$, China $(n=259)$, Japan $(n=75) ;{ }^{\mathrm{b}}$ Among physicians reporting prescribing SABA with MART some of the time, most of the time, or always: Total ( $n=1127)$, Canada ( $n=211)$, France $(n=104)$, Germany $(n=165)$, Australia $(n=209)$, China ( $n=277)$, Japan ( $n=161)$; ${ }^{\circ}$ Excluding physicians responding 'Don't know' or 'Refuse': Total $(n=1283)$, Canada $(n=248)$, France $(n=112)$, Germany $(n=179)$, Australia $(n=269)$, China $(n=281)$, Japan $(n=194)$ 
The majority of physicians (91\% overall) prescribed a SABA or bronchodilator in addition to MART at least some of the time (Fig. 2). A substantial proportion of physicians prescribed additional bronchodilators either most of the time or always (49\% overall, ranging from $21 \%$ in Japan to $75 \%$ in China), while a similar proportion prescribed additional bronchodilators some of the time (42\% overall, ranging from $23 \%$ in China to $63 \%$ in Japan). The primary reason overall (cited by $35 \%$ of physicians) for prescribing additional reliever medication was that it made patients feel safer; patient familiarity with SABA medicine and patient convenience were also commonly selected (Table 4).

Overall, $32 \%$ of physicians did not provide any specific instructions to pharmacies when prescribing MART. Instructions to patients to use the ICS/formoterol combination as relief as well as maintenance were mainly verbal ( $87 \%$ overall) and/or written (59\% overall, varying considerably between countries from $24 \%$ in Japan to $84 \%$ in France). When asked about the time and effort required for MART prescribing compared with other maintenance medications, the majority of physicians reported that 'somewhat more' (40\% overall, ranging from $21 \%$ in France to $45 \%$ in China) or 'about the same' (29\% overall, ranging from $19 \%$ in China to $68 \%$ in France) time and effort was required. However, $13 \%$ of physicians reported that 'somewhat less' time and effort was required (range: $7 \%$ in China to $21 \%$ in Japan) and only 5\% (range: $0 \%$ in France to $7 \%$ in Canada and Australia) reported that 'much less' time and effort was required. The proportion of physicians reporting that 'much more' time and effort was required was low (14\%), ranging from 1\% in France to $24 \%$ in China. The majority of physicians believed that their patients understand MART 'somewhat well' (60\%) or 'very well' (36\%).

\section{Discussion}

Despite variations in asthma management practices among countries, several overall trends were observed. The majority of physicians agreed that the outlook for asthma patients has improved in the last 10 years (mainly through the availability of better and more devices and medications). It is somewhat surprising that physicians did not rate other reasons more highly, such as better understanding of the disease by physicians and patients, education/awareness, adherence to treatment regimens and better engagement of patients in managing their disease. This is despite the clear directions in treatment guidelines for many years that these issues are important in improving asthma care [11]. There was widespread concern about patient adherence, with the main barriers to adherence focusing on patients' lack of understanding of the disease and treatments. Patients' lack of understanding was also the most commonly cited reason for patients not receiving treatment that physicians believed was best for them, while institutional factors (such as cost or insurance coverage) were cited much less frequently. Awareness of MART was high, yet few physicians used this strategy as recommended in the GINA guidelines [11] and as per licence, instead prescribing additional SABAs or bronchodilators.

Considerable variation among countries was observed in preferred methods for assessing asthma control. There was a noticeable discrepancy between the measurements recommended by GINA (frequency of daytime symptoms, night-time awakenings, reliever medication use and extent

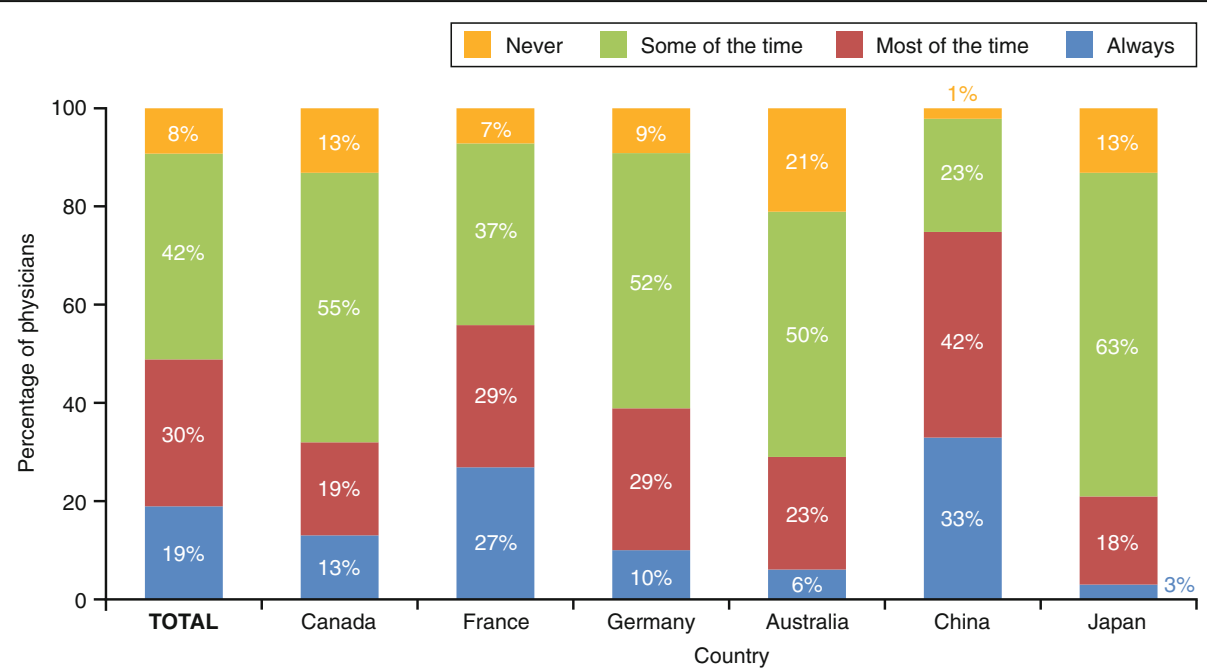

Fig. 2 Prescription of SABAs or bronchodilators in addition to MART. MART, maintenance and reliever therapy; SABA, short-acting $\beta_{2}$-agonist. Percentage values within categories may sum to $<100 \%$ or $>100 \%$ due to rounding and weightings applied 
of activity limitation) [11] and those used in several countries. In particular, physicians in Germany had low use of these GINA measurements, instead mainly using lung function measurements (recommended by GINA for assessing the risk of poor asthma outcomes rather than the level of asthma control [11]) reflecting the advice given in German national guidelines [27, 28]. Physicians in China had relatively high use of the GINA criteria; notably $60 \%$ of physicians used activity limitation to assess control, while in other countries this measure was used by $\leq 21 \%$ of physicians. The reported use of standardised, validated patient-reported outcomes (such as the Asthma Control Test $[\mathrm{ACT}]$ ) was consistently low, particularly in Australia, Canada, China, Germany, and Japan, despite their confirmed reliability $[29,30]$. These findings suggest that the barriers to the integration of guidelines into routine clinical practice need to be addressed through welldesigned interventions with both patients and healthcare providers.

GINA guidelines recommend the use of written action plans for all patients [11]; however, their use was found to be relatively low in this study (30-50\%). In addition, the use of written plans reported was higher than the use of patient-reported outcomes for assessing asthma control, demonstrating that these tools are generally not used together, as advocated by GINA. Technological advances may aid the use of written action plans; however, despite the increasing use of technology in healthcare, its use in asthma management in this study was extremely low, perhaps due to the lack of availability or physician recommendation of suitable digital tools, or a lack of interoperability between digital tools on patient devices and electronic medical record systems. The increasing and reportedly successful use of technology in diabetes management [31] sets an example that might inspire further research into the development and everyday use of suitable digital tools for use in managing asthma.

The overall trends found across the countries can mask some interesting trends found at a national level. This is most evident in China, where the sample population differed from the other countries in terms of physicians' age and gender distributions, and working environment (primary care asthma management is provided by internal medicine physicians in hospitals). Responses of physicians in China often differed from those of physicians in the other countries; in some cases, the considerable differences skewed the overall data. Physicians in China had the highest awareness and use of MART, and unlike in other countries, physicians reported obtaining information about MART from local and national guidelines. Despite this awareness, they also had the highest prevalence of prescribing additional SABAs or bronchodilators with MART, suggesting a possible lack of understanding of the treatment, lack of belief in its effectiveness, or demand from patients for the 'safety net' of having a separate reliever.

Previous surveys of patients with asthma (notably AIR $[6,7,16]$, AIM $[8,17,18,32]$ and REALISE $[9,10])$ have emphasised patients' lack of both understanding of treatment and belief in its effectiveness when used in accordance with guidelines. Patients also communicated low expectations of achievable control and a high tolerance of symptoms, as demonstrated by the discrepancy between patients' assessments of their asthma control and the extent of their control according to guideline criteria [6-10]. This is despite the demonstration that guidelinedefined control is achievable in most patients [33]. The perceived barriers to patient adherence and reasons for patients not receiving the treatment physicians considered best for them reported in this study are consistent with these previous findings, suggesting that most physicians are at least aware of these issues. Some of the perceived barriers to adherence relate to health literacy, emphasising the need to consider this in patient education practices [34].

Another important issue revealed in previous surveys of both patients [32] and physicians [22] is the discrepancy between treatment and management practices recommended in guidelines and those actually experienced by patients. This is due to both a difference in physicians' practices from those advised and a lack of compliance in patients. In terms of treatment, previous surveys have examined use of ICS-containing regimens but not specific use of MART; however, our findings in relation to MART use are consistent with the lack of adherence to guidelines emphasised previously. In terms of management, the low use of written management plans reported in this study, despite their recommendation in guidelines, is consistent with previous findings [32]. This may reflect the debate about the extent of the benefits of written management plans [35] since these benefits were first presented in 2004 [36]. The proportion of physicians employing written plans in Germany recorded in our study (37\%) is lower than published data from the German Disease Management Programme (DMP) evaluation would suggest [37]. Another study reported this discrepancy in use of written plans between German patients enrolled in the DMP and those not enrolled [38], demonstrating both the need to assess a representative population when calculating overall population estimates and the potential benefit of enrollment on such a structured programme. The low use of patient questionnaires for assessing asthma control found in this study is also consistent with previous findings [32], yet the overall or country-specific reasons explaining this remain unclear.

This study has provided data of over 1800 physicians' perspectives over four continents in 2015; however, it is 
limited to countries with higher levels of healthcare resources and, therefore, cannot be generalised to all countries. The physicians included in the sampling frame were generalists; it is possible that the perspectives and behaviours of specialists might differ (for example, a recent study comparing asthma management in different types of physicians in Italy found that use of the ACT was considerably higher in pneumologists and allergologists than in general practitioners [39]). However, the perspectives of generalists are of high importance since patients are most commonly assessed by a general practitioner, at least as a first-line approach. As for all surveys, the results are subject to inaccuracy in physicians' reporting or recall, which would lead to a non-differential bias. A further limitation is the difficulty in capturing fully the impact of the different healthcare systems and the different types of samples in the study results, despite adjustment for sampling weights. The sampling schemes used may have affected the response rates in different countries, and the differences in healthcare systems were likely to have contributed to the observed variations in practice type. Similarly, cultural and study administration differences cannot be excluded as explanations for some of the observed variation between countries. This study presents only the views of physicians; the addition of patients' opinions would have provided more insight, for example, into the difference between patients' understanding as perceived by physicians, and their own reported understanding.

This study primarily revealed the widespread need for improved physician and patient education about asthma. Patient outcomes have been shown to benefit from physicians' continued medical education in asthma $[40,41]$ thus increased education for primary care physicians should be prioritised, particularly in regards to the practices advised in current global and local guidelines for asthma management. This education should focus on the perceived barriers to improved adherence (e.g. educating patients on proper use of medication, identifying asthma symptoms, and inhaler technique), use of written management plans and validated patient questionnaires for assessing asthma control, and on the prescription of medication as indicated in guidelines. Physicians' responses to several questions highlighted their tendency to rely upon advances in therapeutic intervention to improve the quality of asthma care, rather than the non-therapeutic aspects of asthma management (such as the use of written management plans and validated patient-reported outcomes). Future research might be advisable into the time that would be required in a patient consultation to implement guideline recommendations properly, in comparison with the actual time available to primary care physicians for patient consultations.

Effects of physicians' ages and genders on their prescribing practices are perhaps under-investigated; most studies have focused on patient demographics. However, the complex nature of the physician-patient relationship (one study found that patient demographics affected physicians' adherence to guidelines [42]) provides an interesting area for further research. Research into this relationship to date has enabled the development of frameworks for shared decision-making, a collaborative process between physicians and patients aiming to facilitate joint decisions about patients' healthcare management where there are multiple treatment options [43].

Another potential area for future research is the use of electronic devices for monitoring symptoms, health status and medication use which easily integrate with electronic health records and/or pharmacy dispensing data. Digital solutions may enable easier and more accurate monitoring of patients' adherence and asthma control, allowing for early and effective interventions to reduce risks and improve outcomes [44].

\section{Conclusions}

In conclusion, while asthma management practices vary by country, these data suggest that better education for both patients and physicians is required globally, particularly in the use of asthma management plans combined with a much wider use of standardised, validated asthma management tools. Consideration of physicians' perspectives and local challenges, such as varying healthcare systems and cultural preferences, in removing the barriers to allow physicians to deliver guideline-recommended care should ultimately improve asthma outcomes.

\section{Additional files}

Additional file 1: Questionnaire used in the GAPS survey. (PDF 809 kb)

Additional file 2: Table S1. Reasons given for the perceived improved outlook for asthma patients in the last 10 years. Table S2. Products approved for maintenance and reliever treatment of asthma in the countries studied. (PDF 202 kb)

\section{Abbreviations \\ ACT: Asthma Control Test; AIM: Asthma Insight and Management; AIR: Asthma Insights and Reality; DMP: Disease Management Programme; GAPP: Global Asthma Physician and Patient; GAPS: Global Asthma Physician Survey; GINA: Global Initiative for Asthma; ICS: inhaled corticosteroids; LABAs: long-acting $\beta_{2}$-agonists; MART: maintenance and reliever therapy; REALISE: REcognise Asthma and LInk to Symptoms and Experience; SABA: short-acting $\beta_{2}$-agonist; SMART: single maintenance and reliever therapy}

\section{Acknowledgements}

Editorial support in the form of preparation of the first draft based on input from all authors, and collation and incorporation of author feedback to develop subsequent drafts was provided by Elizabeth Jameson, PhD, and Gillian Groeger, PhD, of Fishawack Indicia Ltd, and was funded by GSK.

\section{Funding}

This study was funded by GlaxoSmithKline (study number: PRJ2509).

The funders of the study had a role in study design, data analysis, data 
interpretation, and writing of the report. The study was conducted by the third-party organisation Abt SRBI. The corresponding author had full access to all the data and the final responsibility to submit for publication.

\section{Availability of data and materials}

The data analysed for this study can be made accessible for further research via a scientific proposal to the corresponding author and subject to review process.

\section{Authors' contributions}

KG contributed to the study concept and design and was involved in data acquisition, analysis and interpretation. MA, KRC, KD, MG, TG, DH, JL, PP and CR contributed to the study concept and design and were involved in data analysis and interpretation. All authors were involved in preparation and review of the manuscript and approved the final version to be submitted.

\section{Ethics approval and consent to participate}

The GAPS survey was granted an exemption by the Abt SRBI IRB, as it met the criteria eligible for exemption under 45 CFR 46.101 (b)(2). An IRB for each country was determined to be unnecessary based on the scope and type of the data collection and the target survey population. All participants provided consent to participate in the study, along with any relevant national requirements (where applicable), before the survey was administered.

\section{Consent for publication}

Not applicable.

\section{Competing interests}

$\mathrm{DH}, \mathrm{MG}$ and $\mathrm{KD}$ are employees of GSK and hold stocks/shares in GSK. KG is an employee of Abt SRBI, the company contracted to conduct the survey. KRC, TG, PP, JL, MA and CR served on the Scientific Advisory Committee for GAPS and were paid for advisory services by GSK. KRC is a recipient of research grants and consulting fees from GSK, and receives personal support from the Canadian Institutes of Health Research/GSK partnership Research Chair in Respiratory Health Care Delivery. CR has served on advisory boards for AstraZeneca, ALK, Boehringer Ingelheim, Chiesi, GSK, Intermune, MundiPharma, Novartis and TEVA. JL received speaker's honoraria from GlaxoSmithKline, AstraZeneca and MSD; has been a member of global advisory boards for Boehringer Ingelheim.

\section{Publisher's Note}

Springer Nature remains neutral with regard to jurisdictional claims in published maps and institutional affiliations.

\section{Author details}

${ }^{1}$ University of Toronto, Toronto, Canada. ${ }^{2}$ Real World Evidence \& Epidemiology, GlaxoSmithKline, 1250 South Collegeville Road, Collegeville, PA 19426, USA. ${ }^{3}$ Five Dock Family Medical Practice, Five Dock, Australia. ${ }^{4}$ Bordeaux University, Bordeaux, France. ${ }^{5} \mathrm{Global}$ Respiratory Franchise, GlaxoSmithKline, Brentford, UK. ${ }^{6}$ University Medical Centre Giessen and Marburg, Philipps-University Marburg, Marburg, Germany. ${ }^{7}$ Abt SRBI, Silver Spring, MD, USA. ${ }^{8}$ China-Japan Friendship Hospital, Beijing, China.

${ }^{9}$ International University of Health and Welfare, Tokyo, Japan.

\section{Received: 15 December 2016 Accepted: 10 November 2017}

\section{Published online: 23 November 2017}

\section{References}

1. The Global Asthma Network. The Global Asthma Report 2014. 2014. http:// www.globalasthmareport.org. Accessed May 2016.

2. To T, Stanojevic S, Moores G, Gershon AS, Bateman ED, Cruz AA, et al. Global asthma prevalence in adults: findings from the cross-sectional world health survey. BMC Public Health. 2012;12:204.

3. Aalbers R, Vogelmeier C, Kuna P. Achieving asthma control with ICS/LABA: A review of strategies for asthma management and prevention. Respir Med 2016:111:1-7.

4. Agbetile J, Green R. New therapies and management strategies in the treatment of asthma: patient-focused developments. J Asthma Allergy. 2011:4:1-12.

5. Olin JT, Wechsler ME. Asthma: pathogenesis and novel drugs for treatment. BMJ. 2014;349:95517.
6. Rabe KF, Vermeire PA, Soriano JB, Maier WC. Clinical management of asthma in 1999: the Asthma Insights and Reality in Europe (AIRE) study. Eur Respir J. 2000;16:802-7.

7. Lai CK, De Guia TS, Kim YY, Kuo SH, Mukhopadhyay A, Soriano JB, et al. Asthma control in the Asia-Pacific region: the Asthma Insights and Reality in Asia-Pacific Study. J Allergy Clin Immunol. 2003;111:263-8.

8. Maspero JF, Jardim JR, Aranda A, Tassinari CP, Gonzalez-Diaz SN, Sansores $\mathrm{RH}$, et al. Insights, attitudes, and perceptions about asthma and its treatment: findings from a multinational survey of patients from Latin America. World Allergy Organ J. 2013;6:19.

9. Price $\mathrm{D}$, Fletcher $\mathrm{M}$, van der Molen T. Asthma control and management in 8,000 European patients: the REcognise Asthma and LInk to Symptoms and Experience (REALISE) survey. NPJ Prim Care Respir Med. 2014;24:14009.

10. Price D, David-Wang A, Cho SH, Ho JC, Jeong JW, Liam CK, et al. Time for a new language for asthma control: results from REALISE Asia. J Asthma Allergy. 2015;8:93-103.

11. Global Initiative for Asthma (GINA). Global Strategy for Asthma Management and Prevention. 2016. http://ginasthma.org/ (accessed May 2016).

12. British Thoracic Society. British guideline on the management of asthma - a national clinical guideline. Updated 2014. https://www.brit-thoracic.org.uk (accessed May 2016).

13. Asthma Workgroup Chinese Thoracic Society. Chinese Society of General Practitioners. Chinese guideline for the prevention and management of bronchial asthma (Primary Health Care Version). J Thorac Dis. 2013;5:667-77.

14. Lougheed MD, Lemiere C, Ducharme FM, Licskai C, Dell SD, Rowe BH, et al. Canadian Thoracic Society 2012 guideline update: diagnosis and management of asthma in preschoolers, children and adults. Can Respir J. 2012;19:127-64

15. Kew KM, Karner C, Mindus SM, Ferrara G. Combination formoterol and budesonide as maintenance and reliever therapy versus combination inhaler maintenance for chronic asthma in adults and children. Cochrane Database Syst Rev. 2013:CD009019.

16. Adams RJ, Fuhlbrigge A, Guilbert T, Lozano P, Martinez F. Inadequate use of asthma medication in the United States: results of the asthma in America national population survey. J Allergy Clin Immunol. 2002;110:58-64.

17. Meltzer EO, Blaiss MS, Nathan RA, Doherty DE, Murphy KR, Stoloff SW. Asthma burden in the United States: results of the 2009 Asthma Insight and Management survey. Allergy Asthma Proc. 2012:33:36-46.

18. Asthma Insight and Management in Europe and Canada (EUCAN AIM): A multicountry survey of asthma patients. 2010. http://www.takingaimatasthma. eu/docs/EUCAN_AlM_Highlights.pdf. Accessed 24 June 2016.

19. Su N, Lin J, Chen P, Li J, Wu C, Yin K, et al. Evaluation of asthma control and patient's perception of asthma: findings and analysis of a nationwide questionnaire-based survey in China. J Asthma. 2013;50:861-70.

20. Su N, Lin J, Liu G, Chen P, Zhou X, Wan H, et al. [An epidemiological survey of current asthma control status in China]. Zhonghua Nei. Ke. Za. Zhi. 2014; 53:601-606.

21. Chapman KR, Boulet LP, Rea RM, Franssen E. Suboptimal asthma control: prevalence, detection and consequences in general practice. Eur Respir J. 2008:31:320-5

22. Canonica GW, Baena-Cagnani CE, Blaiss MS, Dahl R, Kaliner MA, Valovirta EJ, et al. Unmet needs in asthma: Global Asthma Physician and Patient (GAPP) Survey: global adult findings. Allergy. 2007;62:668-74.

23. Barthwal MS, Pethe MP. Study of asthma management practices among general practitioners and physicians in and around Pune city. J Indian Med Assoc. 2013;111:840-4

24. Kardas P, Lewek P. Strzondala M. Adherence to treatment in asthma and COPD patients in their doctors' assessment. Pneumonol Alergol Pol. 2015; 83:436-44.

25. van den Berg NJ, of ten Have WH, Nagelkerke AF, Bindels PJ, van der Palen $J$, van Aalderen WM. What general practitioners and paediatricians think about their patients' asthma. Patient Educ Couns. 2005;52:182-5.

26. Price D, David-Wang A, Cho SH, Ho JC, Jeong JW, Liam CK, et al. Asthma in Asia: Physician perspectives on control, inhaler use and patient communications. J Asthma. 2016;53:761-9.

27. German Medical Association, National Association of Statutory Health Insurance Physicians. Association of the Scientific Medical Societies in Germany. Asthma: National Care Guideline; 2009.

28. Buhl R, Berdel D, Criée C-P, Gillissen A, Kardos P, Kroegel C, et al. Guidelines for diagnosis and treatment of asthma patients - German Airway League and German Respiratory Society. Pneumologie. 2006;60:139-83. 
29. Juniper EF, O'Byrne PM, Guyatt GH, Ferrie PJ, King DR. Development and validation of a questionnaire to measure asthma control. Eur Respir J. 1999;14:902-7.

30. Nathan RA, Sorkness CA, Kosinski M, Schatz M, Li JT, Marcus P, et al. Development of the asthma control test: a survey for assessing asthma control. J Allergy Clin Immunol. 2004;113:59-65.

31. David SK, Rafiullah MR. Innovative health informatics as an effective modern strategy in diabetes management: a critical review. Int J Clin Pract. 2016;70:434-49.

32. Nathan RA, Thompson PJ, Price D, Fabbri LM, Salvi S, Gonzalez-Diaz S, et al. Taking aim at asthma around the world: global results of the Asthma Insight and Management Survey in the Asia-Pacific Region, Latin America, Europe, Canada, and the United States. J Allergy Clin Immunol Pract. 2015;3: 734-42. e5

33. Bateman ED, Boushey HA, Bousquet J, Busse WW, Clark TJ, Pauwels RA, et al. Can guideline-defined asthma control be achieved? The Gaining Optimal Asthma ControL study. Am J Respir Crit Care Med. 2004;170:836-44.

34. O'Conor R, Wolf MS, Smith SG, Martynenko M, Vicencio DP, Sano M, et al. Health literacy, cognitive function, proper use, and adherence to inhaled asthma controller medications among older adults with asthma. Chest. 2015;147:1307-15.

35. Sheares BJ, Mellins RB, Dimango E, Serebrisky D, Zhang Y, Bye MR, et al. Do patients of subspecialist physicians benefit from written asthma action plans? Am J Respir Crit Care Med. 2015;191:1374-83.

36. Gibson PG, Powell H. Written action plans for asthma: an evidence-based review of the key components. Thorax. 2004:59:94-9.

37. Mehring M, Donnachie E, Mutschler R, Hofmann F, Keller M, Schneider A. Disease management programs for patients with asthma in Germany: a longitudinal population-based study. Respir Care. 58. 2013;58:1170-7.

38. Steppuhn H, Langen U, Mueters S, Dahm S, Knopf H, Keil T, et al. Asthma management practices in adults - findings from the German Health Update (GEDA) 2010 and the German National Health Interview and Examination Survey (DEGS1) 2008-2011. J Asthma. 2016;53:50-61.

39. Caminati M, Magnoni MS, Rizzi A, Braido F, Foresi A, Bettoncelli G, et al. Asthma management among different specialists: results from a national Italian survey. Eur Ann Allergy Clin Immunol. 2014;46:74-82.

40. Fang X, Li S, Gao L, Zhao N, Wang X, Bai CA. short-term educational program improved physicians' adherence to guidelines for COPD and asthma in Shanghai. Clin Transl Med. 2012;1:13.

41. Cabana MD, Slish KK, Evans D, Mellins RB, Brown RW, Lin X, et al. Impact of Physician Asthma Care Education on patient outcomes. Health Educ Behav. 2014:41:509-17.

42. McKinlay JB, Link CL, Freund KM, Marceau LD, O'Donnell AB, Lutfey KL. Sources of variation in physician adherence with clinical guidelines: results from a factorial experiment. J Gen Intern Med. 2007;22:289-96.

43. Politi MC, Wolin KY, Legare F. Implementing clinical practice guidelines about health promotion and disease prevention through shared decision making. J Gen Intern Med. 2013;28:838-44.

44. Chan AH, Reddel HK, Apter A, Eakin M, Riekert K, Foster JM. Adherence monitoring and e-health: how clinicians and researchers can use technology to promote inhaler adherence for asthma. J Allergy Clin Immunol Pract. 2013;1:446-54.

\section{Submit your next manuscript to BioMed Central and we will help you at every step:}

- We accept pre-submission inquiries

- Our selector tool helps you to find the most relevant journal

- We provide round the clock customer support

- Convenient online submission

- Thorough peer review

- Inclusion in PubMed and all major indexing services

- Maximum visibility for your research

Submit your manuscript at www.biomedcentral.com/submit

CBiomed Central 